\title{
Correlation between serum ferritin levels and attention-deficit/hyperactivity disorder symptom scores in children based on the Abbreviated Conners Teachers Rating Scale
}

\author{
Intan Alita Putri Tumbelaka, Hardiono D Pusponegoro, Rinawati Rohsiswatmo
}

\begin{abstract}
Background Dopamine deficiency is thought to be one of the factors causing attention-deficit/hyperactivity disorder (ADHD) in children. Iron contributes to the regulation of dopamine neurotransmitter activity, thus, iron deficiency has been associated with ADHD. Several studies have been conducted in other countries to assess for a correlation between serum ferritin levels and ADHD symptom scores, but with varied results.

Objective To examine the relationship between iron deficiency and ADHD symptoms, in particular the correlation between serum ferritin levels and Abbreviated Conners Teachers Rating Scale (ACTRS) scores in children with ADHD.

Methods This cross-sectional study was performed in children aged 5-12 years who were newly diagnosed with ADHD. Subjects were recruited from the Klinik Anakku Kelapa Gading, the Neurology Outpatient Clinic, the Growth and DevelopmentSocial Pediatrics Outpatient Clinic, and the Integrated Child Clinic of Cipto Mangunkusumo Hospital. ADHD diagnoses were established using Diagnostic and Statistical Manual of Mental Disorders, $4^{\text {th }}$ edition (DSM-IV). Subjects' parents and teachers were asked to complete the ACTRS instrument sheet. Venous blood specimens were obtained for peripheral blood and serum ferritin level tests.

Results Of the 33 subjects recruited, 23 were male. Subjects' ages ranged from 5-12 years, with a median age of onset of 4 (range $2-10$ ) years. The combined type of ADHD (with inattention and hyperactivity-impulsivity) was more commonly found (20/33) in our subjects. The mean serum ferritin was 51.31 (SD 27.7) $\mathrm{ng} / \mathrm{mL}$. Using $20 \mathrm{ng} / \mathrm{mL}$ as the serum ferritin cutoff value, 5/33 subjects were considered to be iron deficient. Median ACTRS score by parents and teachers were 15 and 15, respectively. Higher scores were found in the combined type subject group than in the
\end{abstract}

inattention type subject group. Median serum ferritin levels of the two ADHD type groups were similar. Median ACTRS scores of parents and teachers tended to be higher in the iron-deficient group (16 and 16, respectively) than in the normal serum iron group (14.5 and 12.5, respectively). Serum ferritin level showed no correlation $(\mathrm{r}=-0.243 ; \mathrm{P}=0.086)$ to the parents' ACTRS score, and no correlation $(\mathrm{r}=-.057 ; \mathrm{P}=0.377)$ to the teachers' ACTRS score.

Conclusion Serum ferritin level showed no correlation to ACTRS scores of parents and teachers, respectively. However, the median ACTRS score was higher in the iron-deficiency group than in the normal iron status group, suggesting that there may be a qualitative relationship between iron deficiency and ADHD symptoms. [Paediatr Indones. 2012;52:329-35].

Keywords: ADHD, iron, ferritin, ACTRS

From the Department of Child Health, University of Indonesia Medical School, Cipto Mangunkusumo Hospital, Jakarta, Indonesia.

Reprint requests to: Intan Alita Putri Tumbelaka, Department of Child Health, University of Indonesia Medical School, Cipto Mangunkusumo Hospital, Jl. Diponegoro 71, Jakarta. Tel +62819-32427314.E-mail: intan.tumbelaka@gmail.com 
A ttention deficit-hyperactivity disorder (ADHD) is a behavioral disorder marked by lack of attention, impulsive behavior, and excessive activity. This psychiatric and behavioral disorder is most often found in children. ${ }^{1}$ Nurifah ${ }^{2}$ found that $5.4 \%$ of children in three primary schools in Jakarta had ADHD. The exact cause of ADHD remains unclear. Dopamine deficiency is thought to be among the various causes of ADHD. ${ }^{1}$ Iron plays a role in the regulation of dopamine neurotransmitter activity, hence, iron deficiency has been associated with a number of neurological and psychiatric disorders, including ADHD.,3,4

A number of studies have looked for a correlation between serum ferritin levels and ADHD symptom scoring, using a variety of scoring systems. Juneja et al..$^{5}$ reported a moderate inverse correlation $(\mathrm{r}=-0.405)$ between ferritin levels and ADHD symptoms based on the Conners Parent and Teacher Rating Scale, but significant correlations were found only for oppositional symptoms (an ongoing pattern of antagonistic, defiant, and hostile behavior toward parents and other authority figures). Calarge et al. ${ }^{6}$ also found significant correlations between ferritin levels and both total and hyperactivity/impulsivity scores using the Swanson, Nolan and Pelham (SNAP) Rating Scale. Other studies reported weak coefficient correlations. We examined the relationship between serum ferritin levels and ADHD symptom scoring using the Abbreviated Conners Teacher Rating Scale (ACTRS). The ACTRS is a short and easy questionnaire which has been validated in the Indonesian language to be sufficient in sensitivity and specificity. ${ }^{\text {? }}$

If low iron levels play a role in $\mathrm{ADHD}$, iron therapy may potentially be given as an alternative to stimulant medications for children with ADHD and iron deficiency. Stimulant medications, the most common therapy considered to be effective for ADHD, have a number of unwanted side effects. The objective of this study was to assess a relationship between iron deficiency and ADHD symptoms, in particular a correlation between serum ferritin levels and ACTRS scores.

\section{Methods}

This cross-sectional study was conducted from May to August 2011 at the Klinik Anakku Kelapa
Gading, the Neurology Outpatient Clinic, the Growth and Development Outpatient Clinic, and the Integrated Clinic, Department of Pediatrics at Cipto Mangunkusumo Hospital. We included children aged 5-12 years, who met the diagnostic criteria for ADHD based on the DSM-IV, were newly diagnosed, and had never received any intervention for ADHD. Subjects' parents provided informed consent. We excluded children with chronic diseases or other inflammatory conditions that might affect iron levels in the body. Subjects were collected by consecutive sampling.

History-taking and careful observations were conducted on the patients newly suspected of having ADHD. The ADHD diagnoses were made based on DSM IV diagnostic criteria. Researchers gave the ACTRS instruments and explanation sheets to be filled by subjects' parents and teachers. Subsequently, children provided venous blood specimens for the peripheral blood and serum ferritin level exams. Blood examinations were conducted in the Prodia laboratory using the ADVIA 2120. photometry colorimetric method for the examination of hemoglobin and the DPC/Immulite 2000 with immunochemiluminescence method for ferritin levels. Data was processed with SPSS version 17.0. Descriptive data was presented in text, graphics, and tables. Median (range) was used to describe most of the data due to the abnormality of most data distribution. Furthermore, statistical analysis was performed to determine the correlation between serum ferritin level and ADHD symptoms using Pearson correlation test for normally distributed data, or Spearman correlation test if the data is not normally distributed.

This study was approved by the Ethics Committee of the Faculty of Medicine at Cipto Mangunkusumo Hospital.

\section{Results}

A total of 33 children with ADHD met the study criteria. Subjects' ages ranged from 5-12 years. The most common type of ADHD found in our subjects (20 out of 33) was the combined type (inattention and hyperactivity-impulsivity). Mean hemoglobin and serum ferritin level were 12.33 (SD 0.7) g/dL and 
51.31 (SD 27.7) $\mathrm{ng} / \mathrm{mL}$, respectively. Iron status was categorized as normal or iron deficient. Subjects with serum ferritin level $<20 \mathrm{ng} / \mathrm{mL}$ were considered to be iron deficient. Most subjects (28/33) had normal iron status; only 5 subjects had iron deficiency. Subjects' parents and teachers filled the ACTRS questionnaire for symptom scoring. Characteristics of the subjects are shown in Table 1.

In terms of the association between type of ADHD and serum ferritin levels, we found that the median serum ferritin level did not much differ between the inattention- and combined-type groups (there were no subjects with hyperactivity-impulsivity type alone). However, the median parents' and teachers' ACTRS scores were higher in the combined type group. The median serum ferritin levels and ACTRS scores by ADHD type are summarized in Table 2.

Table 1. Subjects' characteristics

\begin{tabular}{lc}
\hline Characteristics & $\begin{array}{c}\text { Subjects } \\
\mathrm{n}=33\end{array}$ \\
\hline Sex, $\mathrm{n}$ & 23 \\
$\quad$ Males & $7(5-12)$ \\
Median age of subjects, years (range) & $4(2-10)$ \\
Median age at onset, years (range) & \\
ADHD type, $\mathrm{n}$ & 13 \\
$\quad$ Inattention & 0 \\
$\quad$ Hyperactivity-impulsivity & 20 \\
$\quad$ Combined & $51.31(27.7)$ \\
Mean ferritin (SD), ng/mL & $12.33(0.7)$ \\
Mean hemoglobin (SD), g/dL & \\
Iron status, $\mathrm{n}$ & 5 \\
$\quad$ Iron deficient & 28 \\
$\quad$ Normal & $15(6-28)$ \\
Median parents' ACTRS score (range) & $15(8-22)$ \\
Median teachers' ACTRS score (range) & \\
\hline
\end{tabular}

Table 2. Median (range) serum ferritin level and ACTRS scores according to ADHD type

\begin{tabular}{lcc}
\hline Variables & Inattention type & Combined type \\
\hline Ferritin level, ng/mL & $48.7(11.7-134.7)$ & $48.9(15.5-117.8)$ \\
Parents' ACTRS score & $10(6-14)$ & $18(12-28)$ \\
Teachers' ACTRS score & $10(8-13)$ & $16.50(10-22)$ \\
\hline
\end{tabular}

Table 3. Median of ACTRS score according to iron status

\begin{tabular}{lcc}
\hline Variables & $\begin{array}{c}\text { Iron-deficient } \\
(\mathrm{n}=5)\end{array}$ & $\begin{array}{c}\text { Normal } \\
(\mathrm{n}=28)\end{array}$ \\
\hline Parents' ACTRS score & $16(14-24)$ & $14.5(6-28)$ \\
Teachers' ACTRS score & $16(10-22)$ & $12.5(8-20)$ \\
\hline
\end{tabular}

The median parents' and teachers' ACTRS scores tended to be higher in the iron-deficient group than in the normal iron status group. We did not perform any statistical analysis since the sample size was too small to result in adequate statistical power. The median parents' and teachers' ACTRS scores based on iron status are shown in Table 3.

The distribution of serum ferritin levels and ADHD symptom scoring based on parents' ACTRS scores were normal, so we used the Pearson's correlation test. The analysis revealed no correlation between serum ferritin level and parents' ACTRS scores $(\mathrm{r}=-0.243 ; \mathrm{P}=0.086)$ (Figure 1$)$.

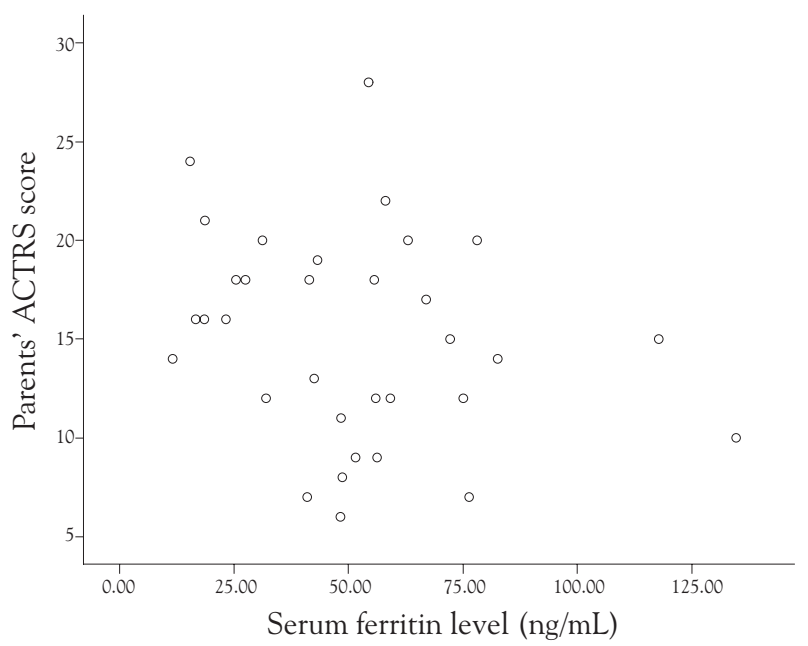

Figure 1. Correlation between serum ferritin level and ADHD symptoms based on parents' ACTRS scores

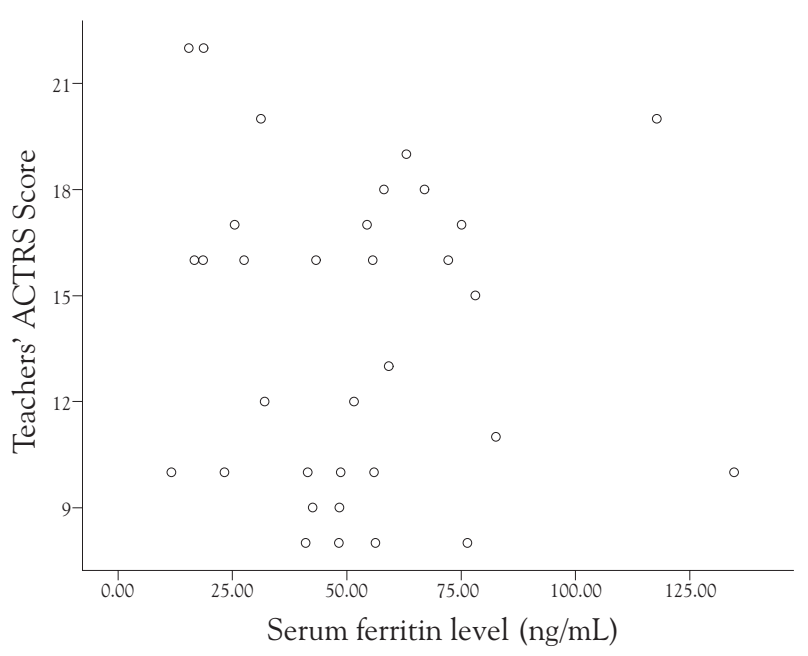

Figure 2. Correlation between serum ferritin level and ADHD symptoms based on teachers' ACTRS scores 
Statistical analysis of a relationship between serum ferritin levels and ADHD symptoms based on teachers' ACTRS was done by Spearman's correlation test. The test revealed no correlation between serum ferritin levels and teachers' ACTRS scores $(\mathrm{r}=-0.057$; $\mathrm{P}=0.377$ ). (Figure 2).

\section{Discussion}

We found no correlation between serum ferritin levels and ACTRS scores, but the median of teachers' and parents' ACTRS scores tended to be higher in iron deficient group than in the normal iron status group. We were unable to statistically analyze mean differences because of the study design and because the sample numbers in the iron-deficient and normal iron status groups were not sufficient.

The use of ferritin to determine iron status was also a limitation in this study. Although serum ferritin is the best and earliest indicator to assess iron reserves and has a high specificity for iron deficiency, ${ }^{8}$ serum ferritin is also an acute-phase protein whose levels are elevated in an inflammatory state, making it difficult to interpret ferritin data in circumstances accompanied by infection or inflammation. ${ }^{9}$ We attempted to find any infectious or inflammatory conditions that affect ferritin levels through historytaking and physical examinations, but these efforts may not have been adequate to detect the presence of inflammation.

School-aged children suffer from ADHD more than other age group, therefore, our subjects were in this age group, ranging from 5 to 12 years, with a median of 7 years. This age was younger than the mean age of subjects reported by Calarge et al. ${ }^{6}$ (10 years), but they used a wider age range (6-14 years) for their inclusion criteria. Most of our subjects (23/33) were male, similar to those in the study by Calarge et al. ${ }^{6}$ who had $83 \%$ males with ADHD. Males tend to experience ADHD more than females. ${ }^{6}$

Based on the history-taking, the onset of ADHD symptoms varied, with a median age of 4 years. To fulfill the ADHD diagnostic criteria of the DSM-IV, symptoms of hyperactivity-impulsivity or inattention must be present before the age of 7 years. Therefore, a median age of 4 years is in agreement with these criteria.
The type of ADHD was categorized into inattention, hyperactivity-impulsivity, or a combination of both types, based on the DSM-IV criteria. Most of our subjects had the combined type of ADHD (20/33). Calarge et al. ${ }^{6}$ reported that $73 \%$ of subjects had the combined type in their study on 59 children with ADHD. The mean ferritin level of our subjects was 51.31 (SD 27.7) $\mathrm{ng} / \mathrm{mL}$, but this number may not reflect the true state of iron stores, since ferritin is an acute phase protein that may be elevated during inflammatory conditions. Similarly, Menegassi et al. ${ }^{10}$ reported mean ferritin levels of $55.2 \mathrm{ng} / \mathrm{mL}$. However, Cortese et al. ${ }^{11}$ reported a mean ferritin level of $38.5 \mathrm{ng} / \mathrm{mL}$ from 68 children with ADHD, while Calarge et al. ${ }^{6}$ reported an even lower mean level of $18.4 \mathrm{ng} / \mathrm{mL}$. The mean hemoglobin level of our subjects was 12.33 (SD 0.7) g/dL, within the range of normal hemoglobin values for children aged $5-14$ years. ${ }^{12}$

Using a cutoff point of $<20 \mathrm{ng} / \mathrm{mL}$ serum ferritin for iron deficiency, 28/33 subjects had normal iron status, while 5/33 subjects had iron deficiency. Similarly, Millichap et al..$^{13}$ found that the prevalence of iron deficiency in pediatric ADHD populations was $18 \%$, using the same cutoff value. With higher cutoff values ( $<30 \mathrm{ng} / \mathrm{mL}$ and $<50 \mathrm{ng} / \mathrm{mL}$ ), the prevalences increased to $44 \%$ and $74 \%$, respectively. ${ }^{13}$ The ferritin cutoff value for diagnosing iron deficiency is still much debated. Some researchers have used higher cutoff values to diagnose iron deficiency in areas with a higher prevalence of malaria and other infections. By using the $30 \mathrm{ng} / \mathrm{mL}$ ferritin cutoff value, Calarge et al. ${ }^{6}$ reported a prevalence of $87 \%$, while Konofal et al. ${ }^{14}$ reported a prevalence of $84 \%$.

The widely used normal ferritin range value is likely to confuse the evaluation of iron status, because it describes the value of normal range in a population and not the biological conditions in the body. ${ }^{15}$ Previous study with bone marrow puncture as the gold standard showed that peripheral iron stores are not completely filled until serum ferritin levels of $>$ $50-100 \mathrm{ng} / \mathrm{mL}$ are reached. Theoretically, the transfer of iron from the peripheral stores, penetrating the blood brain barrier, and entering the central nervous system are affected by the degree of peripheral iron stores saturation. Therefore, ferritin levels that are considered "normal" for the synthesis of hemoglobin 
and myoglobin may not be enough to maintain the function of brain neurotransmitters. ${ }^{16}$ Guyatt et al. ${ }^{15}$ compared serum ferritin levels in adult patients with iron status assessed from bone marrow. In their study, the receiver-operating characteristic (ROC) curve showed $45 \mathrm{ng} / \mathrm{mL}$ to be the optimal cutoff. Ferritin levels below that value demonstrated low peripheral iron stores. Picchietti et al. ${ }^{16}$ also recommended this cutoff value. Furthermore, Cortese et al. ${ }^{11}$ used a ferritin level of $45 \mathrm{ng} / \mathrm{mL}$ as the cutoff value and reported a prevalence of iron deficiency in the ADHD population of $60 \%$. Our use of the cutoff value of $<45 \mathrm{ng} / \mathrm{mL}$ for iron deficiency resulted in an increasing proportion of iron deficient subjects (14/33). This cutoff value may be recommended for use in evaluating iron status for both clinical and research interests in the future, but further study in a pediatric population is needed.

In our study, the median parents' ACTRS score was 15 , and the median teachers' ACTRS score was also 15. Westerlund et al. ${ }^{17}$ in Sweden obtained a mean parents' ACTRS score of 20.83 and teachers' ACTRS score of 15.75 on 12 children with ADHD. The ACTRS was chosen in this study because it has been validated for use in the Indonesian language and is reliable for screening ADHD cases in Indonesia with good sensitivity and specificity. ${ }^{?}$ In addition, this scale consists of only 10 items taken from the Conners teacher rating scale and the Conners parent rating scale, so it is considered to be easier and faster.

The median parents' and teachers' ACTRS scores were higher in subjects with the combined type of ADHD than in subjects with the inattentive type. This result may be due to the individual items on the ACTRS. Items referring to hyperactive/impulsive symptoms are more numerous than items referring to inattentive symptoms. Therefore, subjects with the hyperactive/impulsive type, especially the combined type, will have higher scores than subjects with the inattentive type. By dividing subjects into two groups based on their iron status with a ferritin cutoff of $20 \mathrm{ng} / \mathrm{mL}$, it appeared that the median parents' and teachers' ACTRS score tended to be higher in iron deficiency group. As of yet, we have found no other studies that compared mean ACTRS scores of subjects with iron deficiency to subjects with normal iron status.
We observed no correlation between serum ferritin levels and parents' ACTRS score $(r=-0.243$, $\mathrm{P}=0.086$ ), as well as no correlation with teachers' ACTRS score $(r=-0.057, P=0.377)$. So far we have not found a similar study assessing the correlation between serum ferritin levels and symptom severity using ACTRS. In comparing our results with that of other studies using different instruments, our correlation coefficients were relatively higher than or almost the same as study by Oner et al., ${ }^{18}$ Cortese et al.,11 and Menegassi et al.,10 especially for scores obtained from parents. Cortese et al. ${ }^{11}$ reported no correlation $(r=-0.245)$ using the instrument Connors Parents Rating Scale (CPRS). Oner et al. ${ }^{18}$ reported no correlation between ferritin levels and total CPRS $(\mathrm{r}=-0.19)$, and between ferritin levels and total Connors Teacher Rating Scale (CTRS) $(r=-0.09)$. Menegassi et al. ${ }^{10}$ reported a correlation coefficient of $-0.08(\mathrm{P}=0.72)$ between ferritin and total symptoms scored with the SNAP-rated scale. But compared to the research by Konofal et al., ${ }^{14}$ Juneja et al., ${ }^{5}$ and Calarge et al., ${ }^{6}$ our correlation coefficients were relatively smaller, though equally negative. Konofal et al. ${ }^{14}$ reported a correlation coefficient of -0.34 between serum ferritin levels and CPRS score $(P<0.02)$. In addition, Juneja et al. ${ }^{5}$ reported a correlation coefficient of -0.405 between ferritin levels and the CPRS score and -0.484 between ferritin and CTRS score, but both were significant only for oppositional symptoms. Calarge et al. ${ }^{6}$ obtained a correlation coefficient of -0.31 $(\mathrm{P}=0.04)$ between ferritin levels and the SNAP-rated scale for inattention, -0.42 $(\mathrm{P}<0.006)$ for hyperactivity-impulsivity, and -0.43 $(\mathrm{P}<0.004)$ for total symptom scoring.

The lack of correlation between serum ferritin levels and ACTRS scores may have been influenced by several factors. Normal or high ferritin levels might have been due to inflammatory effects and thus did not reflect a condition of iron stores. In addition, although serum ferritin level is considered to be a measurement of iron store in the body, it remains unclear how well peripheral iron indices correlate with central iron content. ${ }^{19}$ Konofal et al. stated that iron deficiency, mainly occurring in the period of brain development, can result in central nervous system iron misregulation, but this condition might not be adequately detected in measurements of peripheral iron indices. ${ }^{20}$ Cortese 
et al. also stated that the quantity of non-heme iron in the human brain is independent from body iron stores. ${ }^{19}$ Magnetic resonance imaging (MRI) and cerebrospinal fluid analysis may be used to determine the condition of iron deficiency in the brain, but these tests tend to be impractical, invasive, and relatively expensive compared to serum ferritin examination. In addition, studies using these two methods have not been conducted on ADHD populations, as of yet. Earley et al. ${ }^{21}$ showed a decrease in cerebrospinal fluid ferritin levels in patients with restless legs syndrome (RLS), in whom serum ferritin levels did not differ significantly with the control group. Using MRI, Haba-Rubio et al. ${ }^{22}$ showed a decrease of brain iron levels in RLS patients who suffered from haemochromatosis. Different results were reported by Allen et al. ${ }^{23}$ in which RLS patients with decreased iron concentration in the substantia nigra, in proportion to symptom severity. There have been varied results on the correlation of brain and peripheral iron levels. Further study evaluating brain iron levels in ADHD patients needs to be done to confirm the role of these minerals in the pathophysiology of ADHD, as well as to explain the correlation of brain iron with peripheral iron indices, such as ferritin. Despite lack of correlation between low ferritin level and higher ACTRS scores in our study, a relationship between iron deficiency and ADHD symptom severity cannot be ruled out. Since our subjects with iron deficiency had a higher median ACTRS score than that of the normal iron status group, it is possible that the relationship is more qualitative and not fully measurable by ferritin levels.

In conclusion, serum ferritin levels were not correlated with the parents' and teachers' ACTRS scores. However, the mean ACTRS score was found to be higher in the iron-deficient group than in the normal iron status group, so a qualitative relationship between iron deficiency and ADHD symptoms is possible.

\section{Acknowledgments}

We would like to thank all who have helped this study, starting from the preparation of the study, sampling, data processing, to the writing and reporting of research results. In particular, we also thank PT. Nicholas, for providing iron supplements Ferriz ${ }^{\circledR}$ for our iron-deficient subjects.

\section{References}

1. Pusponegoro HD. Gangguan pemusatan perhatian/ hiperaktivitas. In: Lesmana LA, Jacoeb TNA, Sjarif DR, Gunardi H, Setiati S, Alwi I, editors. Naskah lengkap Prosiding Simposium Temu Ilmiah Akbar 2002. Jakarta: Pusat informasi dan penerbitan bagian ilmu penyakit dalam FKUI; 2002. p. 446-60.

2. Nurifah. Prestasi akademik anak usia sekolah dengan gangguan pemusatan perhatian/hiperaktivitas (GPPH) dibandingkan anak bukan GPPH di SDN Cawang Jakarta Timur [master's thesis]. [Jakarta]: Department of Child Health, University of Indonesia Medical School/Cipto Mangunkusumo Hospital; 2006.

3. Bourre JM. Effects of nutrients (in food) on the structure and function of the nervous system: update on dietary requirements for brain. Part 1: Micronutrients. J Nutr Health Aging. 2006;10:377-85.

4. Kane A. ADHD and iron deficiency [cited 2007 March 12]. Available from: http://www.mental-health-matters.com/articles/ article.php? artID $=751$

5. Juneja M, Jain R, Singh V, Mallika V. Iron deficiency in Indian children with attention deficit hyperactivity disorder. Indian Pediatr. 2010;47:955-8.

6. Calarge C, Farmer C, DiSilvestro R, Arnold LE. Serum ferritin and amphetamine response in youth with attention-deficit/ hyperactivity disorder. J Child Adolesc Psychopharmacol. 2010;20:495-502.

7. Yuniar S. Penentuan validitas dan reliabilitas abbreviated Conners' teacher rating scale sebagai penyaring gangguan pemusatan perhatian/hiperaktivitas [master's thesis]. Jakarta: Department of Psychiatry, University of Indonesia Medical School; 1989.

8. Hilman RS, Ault KA. Iron deficiency anemia. In: Morgan J, Hanley P, editors. Hematology in clinical practice. $3^{\text {rd }}$ ed. New York-Toronto: McGraw Hill; 1998. p. 71-84.

9. Worwood M. Indicators of the iron status of populations: ferritin. In: Joint World Health Organization/Centers for Disease Control and Prevention technical consultation on the assessment of iron status at the population level. Assessing the iron status of population. Geneva: WHO Press; 2004. p. 31-73.

10. Menegassi M, Mello ED, Guimaraes LR, Matte BC, Driemeier F, Pedroso GL, et al. Food intake and serum levels of iron in children and adolescents with attention-deficit/hyperactivity disorder. Rev Bras Psiquiatr. 2010;32:132-8.

11. Cortese S, Konofal E, Bernardina BD, Mouren MC, Lecendreux M. Sleep disturbances and serum ferritin levels in children with attention-deficit/hyperactivity disorder. Eur Child Adolesc Psychiatry. 2009;18:303-9. 
12. World Health Organization. Iron deficiency anemia: assessment, prevention, and control [2008 March 8]. Available from http://www.who.int/reproductive-health/docs/ anaemia.pdf

13. Millichap JG, Yee MM, Davidson SI. Serum ferritin in children with attention-deficit hyperactivity disorder. Pediatr Neurol. 2006;34:200-3.

14. Konofal E, Lecendreux M, Arnulf I, Mouren MC. Iron deficiency in children with attention-deficit/hyperactivity disorder. Arch Pediatr Adolesc Med. 2004;158:1113-5.

15. Guyatt GH, Patterson C, Ali M. Diagnosis of iron-deficiency anemia in the elderly. Am J Med. 1990;88:205-9.

16. Picchietti D. Is iron deficiency an underlying cause of pediatric restless legs syndrome and of attention-deficit/ hyperactivity disorder? Sleep Med. 2007;8:693-4.

17. Westerlund J, Ek U, Holberg K, Naswall K, Fernell E. The Conners' 10 -item scale: findings in a total population of Swedish 10-11-year-old children. Acta Paediatrica. 2009;98:828-33.

18. Oner P, Oner O. Relationship of ferritin to symptom ratings children with attention deficit hyperactivity disorder: effect of comorbidity. Child Psychiatry Hum Dev. 2008;39:323-30.

19. Cortese S, Lecendreux M, Bernardina BD, Mouren MC, Sbarbati A, Konofal E. Attention-deficit/hyperactivity disorder, Tourette's syndrome, and restless legs syndrome: the iron hypothesis. Med Hypotheses. 2008;70:1128-32.

20. Konofal E, Cortese S, Marchand M, Mouren MC, Arnulf I, Lecendreux M. Impact of restless legs syndrome and iron deficiency on attention-deficit/hyperactivity disorder in children. Sleep Med. 2007;8:711-5.

21. Earley CJ, Connor JR, Beard JL, Malecki EA, Epstein DK, Allen RP. Abnormalities in CSF concentrations of ferritin and transferrin in restless legs syndrome. Neurology. 2000;54:1698-700.

22. Haba-Rubio J, Staner L, Petiau C, Erb G, Schunck T, Macher JP. Restless legs syndrome and low brain iron levels in patients with haemochromatosis. J Neurol Neurosurg Psychiatry. 2005;76:1009-10.

23. Allen RP, Barker PB, Wehrl F, Song HK, Earley CJ. MRI measurement of brain iron in patients with restless legs syndrome. Neurology. 2001;56:263-5. 